\title{
Use of untargeted metabolomics for assessing soil quality and microbial
} function

Withers, Emma; Hill, Paul W.; Chadwick, David R.; Jones, Davey L.

\section{Soil Biology and Biochemistry}

DOI:

10.1016/j.soilbio.2020.107758

Published: 01/04/2020

Peer reviewed version

Cyswllt i'r cyhoeddiad / Link to publication

Dyfyniad o'r fersiwn a gyhoeddwyd / Citation for published version (APA):

Withers, E., Hill, P. W., Chadwick, D. R., \& Jones, D. L. (2020). Use of untargeted metabolomics for assessing soil quality and microbial function. Soil Biology and Biochemistry, 143, [107758]. https://doi.org/10.1016/j.soilbio.2020.107758

\footnotetext{
Hawliau Cyffredinol / General rights

Copyright and moral rights for the publications made accessible in the public portal are retained by the authors and/or other copyright owners and it is a condition of accessing publications that users recognise and abide by the legal requirements associated with these rights. study or research.

dow public portal for the purpose of private

- You may not further distribute the material or use it for any profit-making activity or commercial gain

- You may freely distribute the URL identifying the publication in the public portal ?
}

Take down policy

If you believe that this document breaches copyright please contact us providing details, and we will remove access to the work immediately and investigate your claim. 
1 Use of untargeted metabolomics for assessing soil quality and microbial function

2

3 Emma Withers ${ }^{\mathrm{a}, *}$, Paul W. Hill ${ }^{\mathrm{a}}$, David R. Chadwick ${ }^{\mathrm{a}, \mathrm{b}}$, Davey L. Jones ${ }^{\mathrm{a}, \mathrm{c}}$

$4 \quad$ a School of Natural Sciences, Environment Centre Wales, Bangor University, Gwynedd, LL57

$5 \quad 2 U W, U K$

6 b Interdisciplinary Research Centre for Agriculture Green Development in Yangtze River

7 Basin, Southwest University, Chongqing, China

$8{ }^{\mathrm{c}}$ SoilsWest, UWA School of Agriculture and Environment, The University of Western Australia,

$9 \quad$ Perth, WA 6009, Australia

10

$11 *$ Corresponding author.

12 E-mail address: e.withers@bangor.ac.uk (E. Withers) 


\section{ABSTRACT}

14 Soils support a wide range of ecosystem services that underpin Earth system functioning. It is therefore essential that we have robust approaches to evaluate how anthropogenic perturbation affects soil quality and the delivery of these services. Metabolomics, the large-scale study of low molecular weight organic compounds in soil, offers one potential approach to characterise soils and evaluate the metabolic status of the soil biological community. The aims of the present study were to 1) characterise the soil metabolome across a contrasting range of soil types, 2) understand the relationships between common chemical and physical soil quality indicators and its metabolome, and 3) evaluate the discriminatory power of soil metabolomics and its potential use as a soil quality indicator. Nine different topsoils with 5 replications were collected along an altitudinal primary productivity gradient encompassing a wide range of soil types and land uses. Metabolites were extracted from soil using 3:3:2 (v/v/v) acetonitrile:isopropanol:water and individual compounds identified using a gas chromatography-mass spectrometry (GC-MS) platform. Overall, 405 individual compounds were detected, of which 146 were positively identified, including sugars, amino acids, organic acids, nucleobases, sugar alcohols, lipids and a range of secondary metabolites. The concentration and profile of metabolites was found to vary greatly between the soil types. Further, the soils' metabolomic fingerprints correlated to a number of environmental factors, including $\mathrm{pH}$, land-use, moisture and salinity. We also tentatively attributed soil-specific metabolites to potential functional pathways, although complementary proteomic, genomic and transcriptomic approaches would be needed to provide definitive supporting evidence. In conclusion, soil metabolomics offers the potential to reveal the complex molecular networks and metabolic pathways operating in the soil microbial community and a means of evaluating soil function. Further work is now required to benchmark soil metabolomes under a wide range of management regimes so that they can be used for the quantitative assessment of soil quality. 
Keywords: Biomarker; Chemical fingerprinting method; Metabolic profiling; Microbial function; Soil health indicator.

40

\section{Introduction}

Soils are central to a wide range of ecosystem services that are essential to earth system functioning (Bünemann et al., 2018). It is therefore essential that we monitor the health of our soils so that the delivery of ecosystem services can be maintained (e.g. nutrient cycling, water purification, food provisioning, climate regulation). While a range of soil quality indicators have been proposed, these are mainly focused on the measurement of standard chemical attributes of the soil (e.g. $\mathrm{pH}$, available $\mathrm{P}$ and $\mathrm{K}$, organic matter content) and the physical characteristics of the soil (e.g. texture, structure, aggregate stability, bulk density; Schloter et al., 2018). However, soil fertility and productivity are not solely a function of the soil's physical and chemical characteristics. Soil organisms are key mediators of many processes linked to plant health and soil productivity. Despite many attempts, the development of robust soil biological quality indicators that can be widely adopted has remained elusive (Schloter et al., 2018). Examples of traditional indicators include measurements of biological activity (e.g. basal and substrate-induced respiration, enzyme activity) and the size and composition of the microbial community (e.g. $\mathrm{CHCl}_{3}$ fumigation-extraction, fatty acid biomarkers) (Bending et al., 2004). The advent of 'omic'-based technologies aimed at the universal detection of genes

57 (genomics), mRNA (transcriptomics), proteins (proteomics) and metabolites (metabolomics), 58 however, offers new ways to evaluate soil biological functioning. While the use of metagenomics and metabarcoding is becoming mainstream (Fierer et al., 2003; George et al., 2019), much less attention has been paid to the metabolomic profiling of soil microbial communities. 
Da) metabolites present within a sample (Vinayavekhin and Saghatelian, 2010). Through recent advances in spectroscopy, it is now feasible to identify and quantify the relative abundance of thousands of metabolites present in biological samples (Patti et al., 2012). A metabolomic approach is similar in cost to genomics and proteomics (Wilson et al., 2005), allows for rapid sample processing (Jones et al., 2013) and is not restricted by unknown degrees of epigenetic regulation and post-translational modifications, respectively (Patti et al., 2012). Additionally, the technique has the capacity to identify biochemical intermediates in interacting metabolic pathways, potentially improving our overall understanding of biological processes operating in soil and improving our ability to predict outcomes (Tang, 2011).

Applications of metabolomics within the environmental sciences extend from organism phenotype characterisation (Bingol et al., 2016; Patti et al., 2012); assessment of responses of plant and soil organismal assemblages to biotic and abiotic factors (Bundy et al., 2003, 2009; Jones et al., 2013, 2014; Trauger et al., 2008); characterisation of differential microbial community structures (Abram, 2015; Graham et al., 2018); and biomarker discovery (Bundy et al., 2009). Combined with complementary '-omics' techniques (genomics, proteomics, transcriptomics), metabolic profiling can provide a better overall understanding of molecular mechanisms associated with environmental cues (Trauger et al., 2008). Applied to the soil microbiome, metabolomics may provide a means of characterising the differential activity of microbial communities (Abram, 2015), reflecting microbial genome-environment interactions

82 (Tang, 2011) and thus a novel way to assess soil health. This can be used to improve our understanding of cellular pathways and community responses to abiotic and biotic stress events as well as providing insights on fundamental soil biochemical functioning (Abram, 2015; Patti et al., 2012; Swenson et al., 2015). 

extent to which this provides functional redundancy in terms of ecosystem service provision, remains relatively unknown (Jurburg and Salles, 2015). Further, little is understood about the soil microbial metabolome, and the degree to which metabolomic fingerprints of soil classes may differ. Untargeted metabolomics analysis may therefore provide a means of assigning phenotype to specific metabolite expression (Guijas et al., 2018); identifying soil-specific microbial nutrient and cellular pathways; and attributing corresponding biological mechanisms and function (Patti et al., 2012; Zhao et al., 2019). Therefore, metabolomics could prove very useful in the assessment of how land use change, climate perturbation and land management regime affects soil health. In this context, the aims of this study were to apply untargeted metabolomics coupled with chemical characterisation to: 1) characterise the soil metabolome across a contrasting range of soil types and land uses, 2) understand the relationships between major chemical and physical characteristics of the soil and its metabolome, 3) evaluate whether metabolomics can provide a suitable indicator of soil quality.

\section{Materials and methods}

\subsection{Soil sampling}

Nine sites with different combinations of soil type and/or vegetation cover were sampled at the start of the growing season (March 2018) across a $350 \mathrm{~m}$ altitudinal gradient (catena sequence) at the Henfaes Experimental Station, Abergwyngregyn, UK $\left(53^{\circ} 14^{\prime} \mathrm{N}\right.$, $04^{\circ} 01^{\prime} \mathrm{W}$; Fig. S1). The sequence of nine soil types along the altitudinal gradient (from 0 to 350 m) were: Saline Alluvial Gley Soil 1, Saline Alluvial Gley Soil 2, Gleyic Sandy Brown Soil, Typical Orthic Brown Soil, Stagno-Orthic Gley Soil, Typical Podzolic Brown Soil 1, Typical Podzolic Brown Soil 2, Typical Humic Ranker Soil and Non-Calcaric Lithosol. The soils were classified on site according to the UK system of Avery (1990). The major properties of the 
sites and soils are shown in Table 1 and in Figure S1, while a general description of the catena sequence is provided in Farrell et al. (2014). The altitudinal gradient also constitutes a primary productivity gradient with more intensive agricultural production at low altitudes. The mean

114 annual temperature at the bottom and top sites was 10.2 and $7.3{ }^{\circ} \mathrm{C}$ respectively, while the

115 gradient in annual rainfall was 1065 to $1690 \mathrm{~mm}$, respectively. All sites had a different vegetation cover (all dominated by grasses) and were grazed by sheep (Ovis aries L.). Land boundaries within which each of the 9 discrete soil types was independently present were identified. Within each boundary, five randomly located independent $5 \mathrm{~cm}$ diameter soil cores (10 cm depth) were removed using a stainless-steel corer and placed in plastic bags. A fixed sampling depth was chosen to reflect national soil monitoring programmes (Bellamy et al., 2005; Emmett et al., 2008). Immediately after collection, the central $1 \mathrm{~cm}^{3}$ was isolated from each core using a sterile spatula, the roots removed and the samples stored in sterile tinfoil cups at $-80^{\circ} \mathrm{C}$ to await metabolome analysis. The remaining soil was retained, placed in plastic bags and stored at $4{ }^{\circ} \mathrm{C}$ for further analysis of the soil properties.

\subsection{Untargeted metabolomics}

The 45 collected soil samples, and 5 blank samples containing no soil, were lyophilized on an Edwards Super Modulyo freeze-drier (SciQuip Ltd., Shropshire, UK) for $7 \mathrm{~d}$. Subsequently, these were ground in a Retsch MM200 stainless steel ball mill (Retsch GmbH, biomass (Fiehn et al., 2002; Wang et al., 2015). The samples were then stored in individual sterile glass vials at $-80^{\circ} \mathrm{C}$ to minimize changes in metabolites (Wellerdiek et al., 2009). The soils were extracted using 3:3:2 (v/v/v) acetonitrile-isopropanol-water, vortexed for 15 seconds, shaken at $4^{\circ} \mathrm{C}$ for 5 minutes, centrifuged at $1400 \mathrm{rpm}$ for 2 minutes, and dried using a 
et al., 2019; Fu et al., 2019). Non-targeted primary metabolism analysis was performed using

137 a Gerstel Automated Linear Exchange-Cold Injection System (ALEX-CIS) with Agilent gas 138 chromatograph (GC) and Leco Pegasus IV Time Of Flight (TOF) MS at the UC Davis West 139 Coast Metabolomics Facility using the method of Fiehn (2016). Briefly, $0.5 \mu$ of each sample 140 was injected onto a Rtx-5Sil MS capillary column $(30 \mathrm{~m}$ length $\times 0.25 \mathrm{~m}$ i.d with $10 \mathrm{~m}$ integrated guard column; $0.25 \mu \mathrm{m}$ 95\% dimethylsiloxane/5\% diphenylpolysiloxane coating;

142 Restek Corp., Bellefonte, PA). Using a He mobile phase, the GC thermal programme was 50

$143{ }^{\circ} \mathrm{C}$ for $1 \mathrm{~min}$, ramped to $330{ }^{\circ} \mathrm{C}$ at $20{ }^{\circ} \mathrm{C} \mathrm{min}{ }^{-1}$ and finally held at $330{ }^{\circ} \mathrm{C}$ for $5 \mathrm{~min}$. Upon 144 elution, samples were injected into a Pegasus IV GC-time of flight mass spectrometer (Leco 145 Corp., St Joseph, MI), using mass resolution of 17 spectra s ${ }^{-1}$, from 80-500 Da, at $-70 \mathrm{eV}$ 146 ionization energy and $1800 \mathrm{~V}$ detector voltage with a $230{ }^{\circ} \mathrm{C}$ transfer line and $250{ }^{\circ} \mathrm{C}$ ion 147 source.

\subsection{General soil properties}

Soil $\mathrm{pH}$ and electrical conductivity (EC) were measured in 1:2.5 (w/v) soil-to-distilled water extracts using standard electrodes. Moisture content was measured gravimetrically by oven drying $\left(105^{\circ} \mathrm{C}, 16 \mathrm{~h}\right)$. Available ammonium and nitrate were determined colorimetrically in 1:5 (w/v) soil-to-0.5 $\mathrm{M} \mathrm{K}_{2} \mathrm{SO}_{4}$ extracts using the salicylic acid procedure of Mulvaney

154 (1996) and vanadate procedure of Miranda et al. (2001), respectively on a Synergy ${ }^{\circledR}$ microplate reader (BioTek Instruments Ltd., Winooski, VT). Total free amino acid concentration in the $0.5 \mathrm{M} \mathrm{K}_{2} \mathrm{SO}_{4}$ extracts was determined fluorometrically using the $o$-phthalaldehyde- $\beta$ mercaptoethanol method of Jones et al. (2002). Available P was determined colorimetrically in 1:5 (w/v) soil-to-0.5 M acetic acid extracts using the molybdate blue method of Murphy and

159 Riley (1962). Exchangeable $\mathrm{Ca}, \mathrm{Na}$ and $\mathrm{K}$ in the $0.5 \mathrm{M}$ acetic acid extracts was determined 160 using a Model 410 flame photometer (Sherwood Scientific Ltd, Cambridge, UK). Total C and 
$161 \mathrm{~N}$ were determined on a TruSpec ${ }^{\circledR} \mathrm{CN}$ analyser (Leco Corp., St Joseph, MI). Dissolved organic $\mathrm{C}$ (DOC) and total dissolved $\mathrm{N}$ (TDN) in the $0.5 \mathrm{M} \mathrm{K}_{2} \mathrm{SO}_{4}$ extracts were determined using a Multi NC 2100S TOC TN analyzer (AnalytikJena, Jena, Germany).

To measure substrate-induced respiration, field moist, root-free soil (5 g) was placed in individual $50 \mathrm{~cm}^{3}$ polypropylene tubes. Subsequently, $1 \mathrm{ml}$ of a ${ }^{14} \mathrm{C}$-labeled glucose solution $\left(1 \mathrm{mM} ; 1.6 \mathrm{kBq} \mathrm{ml}^{-1}\right)$ was added to the soil surface. A vial containing $1 \mathrm{M} \mathrm{NaOH}(1 \mathrm{ml})$ was then suspended above the soil to capture any ${ }^{14} \mathrm{CO}_{2}$ evolved and the tubes hermetically sealed and incubated at $20^{\circ} \mathrm{C}$. The $\mathrm{NaOH}$ traps were replaced after $0.5,1,2$ and $4 \mathrm{~h}$. After removal, the $\mathrm{NaOH}$ was mixed with Optiphase HiSafe 3 scintillation cocktail (PerkinElmer Inc., Waltham, MA) and the ${ }^{14} \mathrm{C}$ quantified on a Wallac 1404 liquid scintillation counter with automated quench correction (Wallac EG\&G, Milton Keynes, UK). The procedure described above was repeated using ${ }^{14} \mathrm{C}$-labelled maize leaf $(50 \mathrm{mg})$ in place of the ${ }^{14} \mathrm{C}$ glucose. In this case the $\mathrm{NaOH}$ traps were replaced after $3 \mathrm{~d}$ (Simfukwe et al., 2011). The turnover of glucose and leaf material were subsequently referred to as labile and more recalcitrant $\mathrm{C}$, respectively.

\subsection{Data and statistical analysis}

The metabolomics data were pre-processed using ChromaTOF (v2.34; Leco Corp.).

Briefly, subtraction of the baseline was applied just above the noise level and automatic mass spectral deconvolution and peak detection applied at a 5:1 signal-to-noise ratio throughout the chromatogram. A BinBase algorithm (rtx5) was applied, spectra were cut to $5 \%$ base peak abundance and matched to database entries. Unmatched peaks were entered as new database entries where the signal-to-noise ratio was $>25$ and purity $<1.0$.

184 Component Analysis (PCA) was applied as an unsupervised method of determining variance within and between soil classes. A pairwise score plot was generated to determine the most 
appropriate combination of Principal Components (PC) to include in the 2D score plot. Biplots

187

188 were generated to visualise the contribution of the loading of each metabolite towards observed variance in the data.

Agglomerative hierarchical clustering analysis was applied to metabolite concentration data and soil classes using two separate methods. Firstly, similarity was determined by Euclidean distance for analysis of the differences in metabolite concentrations, and clustering was performed using Ward's linkage. Secondly, similarity was determined by Pearson's correlation for analysis of the shapes of metabolite expression profiles, and clustering was again performed using Ward's linkage. The dendrograms were combined with a heatmap, generated based on $z$-scores of metabolite concentrations.

A one-way ANOVA coupled with Fisher's LSD method was used to identify significant differences between metabolite concentrations in soil types using a $P<0.05$ cut-off value to denote statistical significance. The same method was applied to identify significant differences between general soil properties observed in different soil types.

\section{Results}

\subsection{Metabolic profile analysis}

Using the methods described, 405 individual metabolites were detected across the nine distinct soil types sampled. 136 metabolites were observed in Saline Alluvial Gley Soil 1 in significantly higher concentrations than the blank control sample $(p<0.05), 181$ in Saline Alluvial Gley Soil 2, 209 in Gleyic Sandy Brown Soil, 143 in Typical Orthic Brown Soil, 232 in Stagno-orthic gley soil, 253 in Typical Podzolic Brown Soil 1, 256 in Typical Podzolic Brown Soil 2, 253 in Typical Humic Ranker Soil, and 319 in Non-Calcaric Lithosol (Fig. S2). 146 of the 405 detected metabolites were positively identified ( $36 \%$ of the total), while 259 showed no match to spectra in the ChromaTOF database. Where PCA was applied to observe 
variance within and between individual soil types, the combination of PC 1 and 2 offered best class separation compared with all other combinations of PCs (Fig. S3). PC 1 and 2 were therefore used to generate 2D PCA scores plots, which separated the nine different soil types 214 into four distinct groupings (Fig. 1, Fig. S4):

215 Group 1. Non-Calcaric Lithosol (NC Lithosol).

216 Group 2. Saline Alluvial Gley Soil 1 (Saline 1) and Saline Alluvial Gley Soil 2 (Saline 2).

217 Group 3. Typical Orthic Brown Soil (TO Brown).

218 Group 4. Gleyic Sandy Brown Soil (Gleyic Sand), Stagno-Orthic Gley Soil (SO Gley), 219 Typical Humic Ranker Soil (Humic Ranker), Typical Podzolic Brown Soil 1 (Podzolic 1) and Typical Podzolic Brown Soil 2 (Podzolic 2).

221 Within the fourth group, a significant difference in variance was observed between the Gleyic Sand and Podzolic 1, and between the Gleyic Sand and Humic Ranker soils. No significant differences in variance could be observed between any other soil types within this group. The majority of metabolites showed strong positive loadings in PC1. The TO Brown soil separated from all the other soil types by a lack of significant contribution from any specific metabolites (Fig. 1, Fig. S5). Both unassigned metabolite 250754 and pipecolinic acid (PIP) contributed significant loadings in the direction of Saline 1 and Saline 2, with the former doing so to a much greater extent (Fig. S5).

\subsection{General soil properties}

In contrast to the metabolite profiles, PCA of general soil properties (Fig. 2) generated just two distinct clusters. Together, Saline 1 and 2 showed significant difference in variance from all other soil types. The remaining seven soil types clustered together, however, a significant difference in variance could be observed between the Gleyic Sand and Podzolic 2, 
and between the Humic Ranker and Podzolic 2. No further discrimination between soil classes could be made through this model.

General soil properties which segregated soil classes included the rate of recalcitrant $\mathrm{C}$ turnover, which generally decreased up the hillslope (Table 1). Soil $\mathrm{pH}$ also generally decreased with increasing altitude: Saline 1 and Saline 2 were alkaline (pH 7 to 9); Gleyic Sand, TO Brown, SO Gley and Podzolic 2 were circum-neutral (pH 5 to 7); and Podzolic 1, Humic Ranker and NC Lithosols were acidic (pH 3 to 5). Total C and N, moisture content and labile $\mathrm{C}$ turnover rate generally increased up the hillslope (Table 1). A similar trend was observed for $\mathrm{NH}_{4}{ }^{+}$content in all soils other than the NC Lithosol, while no clear trend was seen 244 for $\mathrm{NO}_{3}{ }^{-}$.

\subsection{Metabolite concentration}

Based on ANOVA of all detected metabolites (405 in total), significant differences ( $p$ $<0.05)$ were observed between mean concentrations of 344 metabolites in each of the nine distinct soil types (i.e. $86 \%$ of the total; Fig. S6). Where only the 146 known metabolites were considered, a significant difference $(p<0.05)$ was observed between mean concentrations of 140 metabolites (i.e. $96 \%$ of the total; Fig. S7).

Heatmaps (Fig. 3) detail the expression profiles of each soil sample by metabolite concentration $z$-score, based on the top 50 most significant known metabolites assigned by ANOVA (Fig. S7). Clustering metabolites and soil samples by Pearson correlation and Ward's linkage (Fig. 3A) distinguished the Saline 1, Saline 2 and NC Lithosol soils from one another. The same methods distinguished these three soils, within a cluster (Cluster $\mathrm{A}^{1}$ ), from all other soil types. Podzolic 1 and Humic Ranker existed within a single cluster (Cluster $\mathrm{A}^{2}$ ) largely defined by metabolites $\mathrm{N}$-acetyl-D-hexosamine (Nah) to phosphate (excluding undecaprenyl phosphate $\mathrm{N}$-acetylglucosamine; UDP-GlcNAc) being present at the highest concentrations, 

and Podzolic 2 constituted Cluster $\mathrm{A}^{3}$. Soils in Clusters $\mathrm{A}^{2}$ and $\mathrm{A}^{3}$ were more closely related

262 to one another than to Cluster $\mathrm{A}^{1}$ soils. When metabolites and soil samples were clustered by Euclidean distance and Ward's linkage, a different pattern was observed in comparison to method A, producing 6 distinct clusters (Fig. 3B). Briefly, Saline 1 and Saline 2 were clustered independently from one another, within a cluster $\left(\right.$ Cluster $\left.^{2}{ }^{2}\right)$. Occurring within Group 1 , these soils were most closely related to Cluster $\mathrm{B}^{1}$ soils (TO Brown). NC Lithosols clustered independently $\left(\right.$ Cluster $\mathrm{B}^{3}$ ), whilst Podzolic 1 and Humic Ranker soils clustered together $\left(\right.$ Cluster $\mathrm{B}^{4}$ ). Cluster $\mathrm{B}^{4}$ was linked most closely with Group 2, containing Gleyic Sand (Cluster $\left.\mathrm{B}^{5}\right)$, and SO Gley and Podzolic $1\left(\right.$ Cluster $\left.\mathrm{B}^{6}\right)$.

\section{Discussion}

\subsection{Do soil types possess unique metabolomic fingerprints?}

Our results revealed a wide variation in metabolite concentration across the altitudinal gradient. The similarity between the metabolomic profiles for some soil type/vegetation combinations (Fig. 1), however, indicated that each site was not unique. This is similar to genomic-based measurements of soil microbial (e.g. bacteria, fungi, archaea) and mesofaunal communities which also showed that some of these soil types do not possess unique biological fingerprints (George et al., 2019). In this latter study, separation in communities was more related to vegetation cover, soil $\mathrm{pH}$ and organic matter content than soil type per se. Metabolomic profiling by GC-MS therefore does not appear to provide a means of uniquely defining soils, but does allow clustering of soils with similar biochemical properties. As metabolomic analysis provides a signature of functional metabolic processes (Bundy et al., 2009; Patti et al., 2012), our results support the view that considerable functional redundancy exists across soil classes. This is consistent with the view that (i) the primary metabolism of 
soil organisms is likely to be similar, irrespective of soil type, and (ii) many soils share a common core microbiome, particularly when the vegetation cover is similar (Bergmann et al., 2011; Barberan et al. 2012; Jones et al., 2018). It is possible that separation on secondary, rather than primary, metabolites might facilitate greater sample separation, however, this requires an advancement in analytical capability. Although we quantified 405 individual metabolites, this probably represents a tiny fraction of the low molecular weight compounds actually present in our soils. For example, in animal- and plant-based metabolomic studies the number of compounds identified can be >1000 (Huan et al., 2016; Mahieu and Patti, 2017), suggesting the need to improve the extraction efficiency of solutes from soil and to pre-concentrate them prior to analysis. Continual advances in GC-MS analytical resolution and chemical reference libraries should also enhance the resolution of the technique and reduce the proportion of unknown compounds (Mahieu and Patti, 2017; Wishart, 2019). studied topsoils. Typically, soil classification systems use both diagnostic topsoil and subsoil characteristics (e.g. gleyed or podzolic B horizons). It is therefore recommended that the sampling of multiple soil horizons be undertaken to increase the potential to discriminate between soil types.

302

4.2. Does metabolomics provide greater discriminatory power than conventional soil quality indicators?

Traditional soil quality indicators (SQIs) allowed us to segregate the nine soils into just two distinct groups whereas metabolomics identified four distinct clusters (Figs. 1-2), indicating that metabolomics provides greater classification power. The clusters we identified were also similar to those determined from microbial substrate use profiles across 500 sites 
310 also revealed significant crossover between soil types but identified 4 distinct soil groupings,

311 based mainly on $\mathrm{pH}$ and organic matter status, namely: organic, organo-mineral, acid mineral,

312 and neutral mineral soils (Seaton et al., 2019). Although we did not have any organo-mineral

313 soils, these are also relatively consistent with our groupings: the $>15 \%$ TC coupled with a $\mathrm{pH}$

314 range $3-5$ observed in $90 \%$ of organic soils matches the $29.14 \%$ TC and $\mathrm{pH} 4.27$ measured in

315 NC Lithosol; the $<11 \%$ TC coupled with a pH range $4.2-7.5$ observed in $90 \%$ of neutral

316 mineral soils matches the $3.62 \% \mathrm{TC}$ and $\mathrm{pH} 5.78$ measured in TO Brown; and the < $11 \% \mathrm{TC}$

317 coupled with a pH range $4.3-6.8$ observed in $90 \%$ of acid mineral soils approximately matches

318 the $2.64-11.57 \%$ TC and pH $4.37-5.68$ measured in Gleyic Sand, Podzolic 1, Podzolic 2

319 Humic Ranker and SO Gley (Table 1, Fig. 1). Of note is that this previous study did not capture

320 the saline grouping identified in our study.

321 Separation between Clusters $\mathrm{B}^{4}$ and $\mathrm{B}^{5}$ with Cluster $\mathrm{B}^{6}$ through agglomerative

322 clustering by Euclidean distance (Fig. 3) contrasts with the lack of significant differences in

323 variance observed between the respective soil classes through PCA (Fig. 1). Based on PCA,

324 the metabolomic profiles of the members of each cluster overlaps, however, the dendrogram

325 indicates that metabolite concentrations of within-cluster soils are more similar to one another

326 than to metabolite concentrations of soil classes in different clusters. Colouring of the heatmap

327 indicates that clustering of these soil classes is largely based upon high metabolite

328 concentrations in Cluster $\mathrm{B}^{4}$; medium concentrations in Cluster $\mathrm{B}^{6}$; and relatively low

329 concentrations in Cluster $\mathrm{B}^{5}$ (Fig. 3). The lack of significant difference observed between

330 general soil properties (Fig. S8) measured in each of these three clusters indicates that no

331 measured characteristic is solely responsible for this metabolomic variation. Metabolomic

332 differences may therefore be explained by the combined influence of multiple factors, or due

333 to unmeasured characteristics. 

indicates that this metabolite is specific to these soils, implying potential relevant function.

336 Identification of unassigned metabolites may shed light on specific microbial functional 337 pathways, or help identify biomarkers indicative of specific environmental conditions. 338 Combining the powers of MS, for empirical formula, with 2D NMR, for structural distinction 339 between isomers, as described by Bingol and Brüschweiler (2017), could also provide a more 340 powerful means of identifying relevant function. Although unidentified metabolites

341 contributed towards class variance, class distribution did not change significantly when all 342 detected metabolites were included in the PCA model (Fig. S4). Metabolomic class separation 343 through this model does not therefore appear limited by our inability to positively identify all 344 the metabolites in a sample.

345 The majority of assigned metabolites (Fig. S9) included phenolics, organic acids, amino 346 acids and sterols. Uncharged organic molecules such as sterols and lipids typically volatilise 347 readily: a requirement for separation by GC (Lin et al., 2006). Non-volatile molecules 348 containing acidic or basic groups can be volatilised through derivatization (Fiehn, 2016) as 349 conducted in our study (Fiehn et al., 2008). Alongside other derivatization agents, $N$-methyl$350 N$-(trimethylsilyl)trifluoroacetamide was used due to its compatibility with small molecules 351 exhibiting a broad range of functional groups (Aretz and Meierhofer, 2016; Fiehn, 2016). The 352 lack of identified metabolites containing thiol or extremely basic, charged amine groups, 353 however, indicates that such metabolites may not have been effectively derivatized. This 354 potential omission of these metabolites may have reduced the resolution of the study: 355 undetected metabolites may be influential in soil class separation. Although GC-MS holds 356 advantages over LC-MS and NMR in terms of the size of spectral databases and spectral 357 resolution (Fiehn, 2016; Pan and Raftery, 2007; Sumner et al., 2015; Tang, 2011), parallel 
metabolomics studies using these techniques would be advised to improve metabolite coverage, as demonstrated by Psychogios et al. (2011).

\subsection{Sampling considerations}

The number of replicates used in this study $(n=5)$ was below the lower end of recommendations for PCA (Barrett and Kline, 1981; Comrey and Lee, 2016), however, it did reflect typical soil monitoring programmes. Combined with a low sample-to-variable ratio (Osborne and Costello, 2004), the inter-class differences and similarities inferred through PCA may exist due to error induced by model instability. Accumulation of a larger database of samples analysed using the same methods may therefore be beneficial in reducing PCA model error. This may also reduce error introduced due to the inherent variability within each soil type; significant local environmental factors may have impacted metabolomic profile to a greater extent than soil type. To remedy this, it would be preferential to obtain multiple replicates at each sampling site, and sample from more sites per soil type, consistent with current methods in soil molecular ecology (e.g. Docherty et al., 2015; Lauber et al., 2009; Pershina et al., 2018). If the same sites were sampled over time and analysed independently, a reference control would also have been beneficial for quality assurance purposes (Beger et al., 2019). With a view to defining soil quality through metabolomics, collecting samples of each soil type at a range of depths, on different days and in different seasons may reduce further error introduced through temporal variation in root and microbial activity (Fierer et al., 2003; Preston and Basiliko, 2016; Žifčáková et al., 2016). This is also supported by evidence that rhizodeposition, one of the largest inputs of soil $\mathrm{C}$, is highly responsive to the prevailing conditions (Jones et al., 2009).

\subsection{Can we infer function from metabolomic profiles?}


A major limitation of this type of study is its snapshot approach to analysing metabolomic profiles. It cannot be concluded whether observed metabolite accumulations existed due to enhanced activity of the pathway through which a metabolite was synthesised (due to slowing of the metabolic process occurring immediately post-synthesis) or due to alteration of transport systems into or out of the cell. Further, the accumulation of a metabolite at one step in a metabolic pathway may have been masked by its presence at normal concentrations in any number of other pathways. Complementary analysis of metabolic flux may therefore have generated a better idea of metabolic network dynamics (Aretz and Meierhofer, 2016; Jeong et al., 2017) through methods such as real-time NMR or MS combined with stable isotopes (Ebrahimi et al., 2016; Link et al., 2015). Further, a metabolomic profile alone cannot provide a complete understanding of interacting molecular pathways and their modes of regulation: increase or decrease in metabolite levels cannot definitively infer functional change. Complementary genomic, proteomic or transcriptomic studies (Trauger et al., 2008) may therefore contribute towards a more holistic understanding of soil microbial regulation and function. This could also be supported by metabolomic profiles of the primary inputs of $\mathrm{C}$ to the system.

\subsection{Could metabolite expression patterns be used to identify microbial stress responses?}

Metabolite accumulation in cells may be expected to occur in response to stress, or due to an imbalance between the kinetics of steps throughout a metabolic pathway (Sheldon et al., 2016; Cao et al., 2019). One of the best examples of the former is the production of osmo- and cryo-protectants in response to extreme temperature and moisture conditions (Warren, 2014; Min et al., 2018). In contrast, there are few metabolomic studies on kinetic imbalance in soil, although stoichiometric imbalances in $\mathrm{N}, \mathrm{P}$ and $\mathrm{C}$ supply have been shown to greatly alter the metabolite profile in freshwater sediments (e.g. accumulation of $\mathrm{C}$ storage compounds or 
organic acids; Brailsford et al., 2019). The lack of significantly high or low values obtained for stress-linked properties in the TO Brown soil (Table 1) may therefore indicate a lack of environmental stress, allowing for optimal microbial metabolism. This is consistent with the high level of available nutrients (due to fertilizer addition), moderate $\mathrm{pH}$, high rates of primary productivity and organic matter turnover at this site (Table 1), indicating that metabolic rate is not limited through respective deficiencies or acidity. As Pearson correlation separates clusters based on metabolic expression patterns, the presence of TO Brown within Cluster $\mathrm{A}^{3}$ (Fig. 3A) indicates that equivalent metabolic processes may be occurring in all other Cluster $\mathrm{A}^{3}$ soils. This implies that Gleyic Sand, SO Gley and Podzolic 2 are not exhibiting specific stress responses. Metabolite accumulation in these soils may instead be due to slowing of the more vulnerable steps in metabolic pathways, or due to $\mathrm{NO}_{3}{ }^{-}$or $\mathrm{P}$ deficiency-induced rate limitation. Where Group 2 soils are compared with Cluster B ${ }^{4}$ (Fig. 3B), significant differences can be observed in $\mathrm{pH}$ and DOC (Fig. S8). As DOC also differs significantly between SO Gley and Podzolic 2 (both members of Cluster $\mathrm{B}^{6}$ ), but $\mathrm{pH}$ does not, $\mathrm{pH}$ appears most influential. This may be expected; $\mathrm{pH}$ is considered the dominant influencer of soil microbial community assemblage and C use efficiency (Fierer, 2017; Griffiths et al., 2011; Jones et al., 2019). Cluster $\mathrm{B}^{4}$ and Group 2 also differ in land-use and vegetation cover, consisting of unimproved and improved pasture, respectively, and dominated by Vaccinium myrtillus/Ulex europaeus and grassland, respectively (Fig. S1). The occurrence of members of Cluster $\mathrm{B}^{4}$ and Group 2 in separate clusters (Clusters $\mathrm{A}^{2}$ and $\mathrm{A}^{3}$, respectively), through Pearson's correlation (Fig. 3A), indicates that a significantly different pattern of metabolite expression is observed in these soils. As Cluster $\mathrm{A}^{3}$ soils do not appear to be exhibiting specific stress responses (as previously discussed) a pH-, agricultural improvement- or vegetation cover-induced stress response may be occurring in Cluster $\mathrm{A}^{2}$ soils. The main difference between expression profile shape of Cluster $\mathrm{A}^{2}$ and Cluster $\mathrm{A}^{3}$ is the higher concentrations of metabolites Nah to mannose in the 
former (Fig. 3A). This may suggest a relationship between these metabolites and the implied

434

435

436

437

438

439

440

441

442

443

444

445

446

447 stress response. An equivalent response is also apparent in NC Lithosols. This may be expected due to equivalent $\mathrm{pH}$ (Table 1), lack of agricultural improvement and non-grassland cover, when compared with Cluster $\mathrm{A}^{2}$ soils.

The above discussion highlights that much more work is needed to explore how the metabolome responds to a range of management factors and external stressors. This information can then be used to benchmark soil metabolomic responses. It may also allow us to identify specific biomarkers rather than relying on a fingerprinting approach.

\section{Conclusions and future perspectives}

Based on this study, the inter-class variance between the metabolomic profiles of different soil classes, as defined by GC-MS, is not sufficient to uniquely define soil quality. An increased number of samples per class may improve PCA model stability, however, more accurately distributing variance. By combining this with metabolic flux analysis and complementary metabolomics through LC-MS or NMR, a more robust dataset may be produced, maintaining the potential for metabolomics to gauge soil quality.

The number of detected but unassigned metabolites observed in our study emphasises current limitations in terms of metabolite library sizes. Although these did not greatly impact the patterns of inter-class variance, the nature of unassigned metabolites may be significant in broadening current understandings of soil microbial function, or for biomarker discovery. Structure elucidation through targeted MS coupled with NMR may therefore be considered critical for more rigorous metabolomic characterisation.

Our results also show that the metabolome may respond to environmental influences such as $\mathrm{pH}$, land-use, moisture and Na content. Coupling the metabolomic profiles of discrete soil classes with measured characteristics has therefore allowed for direction of future studies 
through attribution of metabolite expression profiles to soil characteristics and molecular pathways. Enzyme kinetics and binding studies may also allow for identification of specific regulatory mechanisms that dictate metabolite expression associated with function. Combined with genomics, proteomics and transcriptomics, distinction could more readily be made between metabolite-induced enzyme inhibition and genomic or proteomic regulation.

Coupling metabolomics with the described combination of techniques therefore holds great potential to provide an in-depth and holistic understanding of soil microbial molecular pathways and their association with environmental cues. Gaining understanding here may have implications regarding biomolecular dynamics and nutrient cycling linked to ecosystem service provision. The understanding gained through metabolomics and complementary experimental methodologies may therefore provide a basis for management guidelines and direct more sustainable intensification in a functional landscape.

\section{Acknowledgements}

This work was carried out under the DOMAINE Project funded by the UK Natural Environment Research Council (NE/K010689/1). Metabolomics analysis was provided by the West Coast Metabolomics Centre.

\section{References}

Abram, F., 2015. Systems-based approaches to unravel multi-species microbial community functioning. Computational and Structural Biotechnology Journal 13, 24-32.

Aretz, I., Meierhofer, D., 2016. Advantages and pitfalls of mass spectrometry based metabolome profiling in systems biology. International Journal of Molecular Sciences 17, 632.

Avery, B.W., 1990. Soils of the British Isles. CAB International, Wallingford, UK. 
Barberan, A., Bates, S.T., Casamayor, E.O., Fierer, N., 2012. Using network analysis to explore co-occurrence patterns in soil microbial communities. ISME Journal 6, 343-351.

Barrett, P., Kline, P., 1981. The observation to variable ratio in factor analysis. Personality Study \& Group Behaviour 1, 23-33.

Barupal, D.K., Zhang, Y., Shen, T., Fan, S.L., Roberts, B.S., Fitzgerald, P., Wancewicz, B., Valdiviez, L., Wohlgemuth, G., Byram, G., Choy, Y.Y., Haffner, B., Showalter, M.R., Vaniya, A., Bloszies, C.S., Folz, J.S., Kind, T., Flenniken, A.M., McKerlie, C., Nutter, L.M.J., Lloyd, K.C., Fiehn, O., 2019. A comprehensive plasma metabolomics dataset for a cohort of mouse knockouts within the international mouse phenotyping consortium. Metabolites 9, 101.

Beger R.D., Dunn, W.B., Bandukwala, A., Bethan, B., Broadhurst, D., Clish, C.B., Dasari, S., Derr, L., Evans, A., Fischer, S., Flynn, T., Hartung, T., Herrington, D., Higashi, R., Hsu, P.C., Jones, C., Kachman, M., Karuso, H., Kruppa, G., Lippa, K., Maruvada, P., Mosley, J., Ntai, I., O'Donovan, C., Playdon, M., Raftery, D., Shaughnessy, D., Souza, A., Spaeder, T., Spalholz, B., Tayyari, F., Ubhi, B., Verma, M., Walk, T., Wilson, I., Witkin, K., Bearden, D.W., Zanetti, K.A., 2019. Towards quality assurance and quality control in untargeted metabolomics studies. Metabolomics 15, 4.

Bellamy, P.H., Loveland, P.J., Bradley, R.I., Lark, R.M., Kirk, G.J.D., 2005. Carbon losses from all soils across England and Wales 1978-2003. Nature 437, 245-248.

Bending, G.D., Turner, M.K., Rayns, F., Marx, M.-C., Wood, M., 2004. Microbial and biochemical soil quality indicators and their potential for differentiating areas under contrasting agricultural management regimes. Soil Biology and Biochemistry 36, 17851792. 
Bergmann, G.T., Bates, S.T., Eilers, K.G., Lauber, C.L., Caporaso, J.G., Walters, W.A., Knight, R., Fierer, N., 2011. The under-recognized dominance of Verrucomicrobia in soil bacterial communities. Soil Biology \& Biochemistry 43, 1450-1455.

Bingol, K., Bruschweiler-Li, L., Li, D., Zhang, B., Xie, M., Brüschweiler, R., 2016. Emerging new strategies for successful metabolite identification in metabolomics. Bioanalysis 8 , $557-573$

Bingol, K., Brüschweiler, R., 2017. Knowns and unknowns in metabolomics identified by multidimensional NMR and hybrid MS/NMR methods. Current Opinion in Biotechnology 43, 17-24.

Brailsford, F.L., Glanville, H.C., Golyshin, P.N., Marshall, M.R., Lloyd, C.E., Johnes, P.J., Jones, D.L., 2019. Nutrient enrichment induces a shift in dissolved organic carbon (DOC) metabolism in oligotrophic freshwater sediments. Science of the Total Environment 690, 1131-1139.

Bundy, J.G., Davey, M.P., Viant, M.R., 2009. Environmental metabolomics: a critical review and future perspectives. Metabolomics 5, 3-21.

Bundy, J.G., Ramløv, H., Holmstrup, M., 2003. Multivariate metabolic profiling using ${ }^{1} \mathrm{H}$ nuclear magnetic resonance spectroscopy of freeze-tolerant and freeze-intolerant earthworms exposed to frost. Cryo-Letters 24, 347-358.

Bünemann, E.K., Bongiorno, G., Bai, Z., Creamer, R.E., De Deyn, G., de Goede, R., Fleskens, L., Geissen, V., Kuyper, T.W., Mäder, P., Pulleman, M., Sukkel, W., van Groenigen, J.W., Brussaard, L., 2018. Soil quality - A critical review. Soil Biology and Biochemistry 120, 105-125.

Cao, Y.W., Qu, R.J., Miao, Y.J., Tang, X.Q., Zhou, Y., Wang, L., Geng, L., 2019. Untargeted liquid chromatography coupled with mass spectrometry reveals metabolic changes in nitrogen-deficient Isatis indigotica Fortune. Phytochemistry 166, 112058. 
531 Chong, J., Soufan, O., Li, C., Caraus, I., Li, S., Bourque, G., Wishart, D.S., Xia, J., 2018.

532 MetaboAnalyst 4.0: Towards more transparent and integrative metabolomics analysis.

$533 \quad$ Nucleic Acids Research 46, W486-W494.

534 Comrey, A.L., Lee, H.B., 2016. A First Course in Factor Analysis. Psychology Press Ltd., $535 \quad$ Hove, UK.

536 Docherty, K.M., Borton, H.M., Espinosa, N., Gebhardt, M., Gil-Loaiza, J., Gutknecht, J.L.M., Maes, P.W., Mott, B.M., Parnell, J.J., Purdy, G., Rodrigues, P.A.P., Stanish, L.F., Walser, O.N., Gallery, R.E., 2015. Key edaphic properties largely explain temporal and geographic variation in soil microbial communities across four biomes. PLOS ONE 10, $\mathrm{e} 0135352$.

Ebrahimi, P., Larsen, F.H., Jensen, H.M., Vogensen, F.K., Engelsen, S.B., 2016. Real-time metabolomic analysis of lactic acid bacteria as monitored by in vitro NMR and chemometrics. Metabolomics 12, UNSP 77.

544 Emmett, B.A., Frogbrook, Z.L., Chamberlain, P.M., Griffiths, R., Pickup, R., Poskitt, J., Reynolds, B., Rowe, E., Rowland, P., Spurgeon, D., Wilson, J., Wood, C.M., 2008. Countryside Survey. Soils Manual. NERC/Centre for Ecology \& Hydrology, CS Technical Report No.3/07, CEH Project Number: C03259, 180 pp.

Farrell, M., Macdonald, L.M., Hill, P.W., Wanniarachchi, S.D., Farrar, J., Bardgett, R.D., Jones, D.L., 2014. Amino acid dynamics across a grassland altitudinal gradient. Soil Biology \& Biochemistry 76, 179-182.

Fiehn, O., 2016. Metabolomics by gas chromatography-mass spectrometry: combined targeted and untargeted profiling. Current Protocols in Molecular Biology 114, 30.4.1-30.4.32.

Fiehn, O., Kopka, J., Trethewey, R.N., Willmitzer, L., 2002. Identification of uncommon plant metabolites based on calculation of elemental compositions using gas chromatography and quadrupole mass spectrometry. Analytical Chemistry 72, 3573-3580. 
556 Fiehn, O., Wohlgemuth, G., Scholz, M., Kind, T., Lee, D.Y., Lu, Y., Moon, S., Nikolau, B.,

557

558

559

560

561

562

563

564

565

566

567

568

569

570

571

572

573

574

575

576

577

578

579 2008. Quality control for plant metabolomics: Reporting MSI-compliant studies. Plant Journal 53, 691-704.

Fierer, N., 2017. Embracing the unknown: disentangling the complexities of the soil microbiome. Nature Reviews Microbiology 15, 579-590.

Fierer, N., Schimel, J.P., Holden, P.A., 2003. Variations in microbial community composition through two soil depth profiles. Soil Biology \& Biochemistry 35, 167-176.

Fu, J., Gong, Z., Kelly, B.C., 2019. Metabolomic profiling of zebrafish (Danio rerio) embryos exposed to the antibacterial agent triclosan. Environmental Toxicology and Chemistry 38, 240-249.

George, P.B.L., Lallias, D., Creer, S., Seaton, F.M., Kenny, J.G., Eccles, R.M., Griffiths, R.I., Lebron, I., Emmett, B.A., Robinson, D.A., Jones, D.L., 2019. Divergent national-scale trends of microbial and animal biodiversity revealed across diverse temperate soil ecosystems. Nature Communications 10, 1107.

Graham, E.B., Crump, A.R., Kennedy, D.W., Arntzen, E., Fansler, S., Purvine, S.O., Nicora, C.D., Nelson, W., Tfaily, M.M., Stegen, J.C., 2018. Multi 'omics comparison reveals metabolome biochemistry, not microbiome composition or gene expression, corresponds to elevated biogeochemical function in the hyporheic zone. Science of The Total Environment 642, 742-753.

Griffiths, R.I., Thomson, B.C., James, P., Bell, T., Bailey, M., Whiteley, A.S., 2011. The bacterial biogeography of British soils. Environmental Microbiology 13, 1642-1654.

Guijas, C., Montenegro-Burke, J.R., Warth, B., Spilker, M.E., Siuzdak, G., 2018. Metabolomics activity screening for identifying metabolites that modulate phenotype. Nature Biotechnology 36, 316-320. 
580 Huan, T., Troyer, D.A., Li., L., 2016. Metabolite analysis and histology on the exact same tissue: comprehensive metabolomic profiling and metabolic classification of prostate cancer. Scientific Reports 6, 32272.

583 Jeong, S., Eskandari, R., Park, S.M., Alvarez, J., Tee, S.S., Weissleder, R., Kharas, M.G., Lee, 584 H., Keshari, K.R., 2017. Real-time quantitative analysis of metabolic flux in live cells 585 using a hyperpolarized micromagnetic resonance spectrometer. Science Advances 3, 586 e1700341.

587

Jones, D.L., Owen, A.G., Farrar, J.F., 2002. Simple method to enable the high resolution determination of total free amino acids in soil solutions and soil extracts. Soil Biology \& Biochemistry 34, 1893-1902.

Jones, D.L., Nguyen, C., Finlay, R.D., 2019. Carbon flow in the rhizosphere: carbon trading at 591 the soil-root interface. Plant and Soil 321, 5-33.

592

Jones, D.L., Hill, P.W., Smith, A.R., Farrell, M., Ge, T., Banning, N.C., Murphy, D.V., 2018. Role of substrate supply on microbial carbon use efficiency and its role in interpreting soil microbial community-level physiological profiles (CLPP). Soil Biology \& Biochemistry 123, 1-6.

Jones, D.L., Cooledge, E.C., Hoyle, F.C., Griffiths, R.I., Murphy, D.V., 2019. pH and 597 exchangeable aluminum are major regulators of microbial energy flow and carbon use efficiency in soil microbial communities. Soil Biology \& Biochemistry in press.

599 Jones, O.A.H., Maguire, M.L., Griffin, J.L., Dias, D.A., Spurgeon, D.J., Svendsen, C., 2013. 600 Metabolomics and its use in ecology. Austral Ecology 38, 713-720. J.L., 2014. Metabolomic analysis of soil communities can be used for pollution assessment. Environmental Toxicology and Chemistry 33, 61-64. 
604 Jurburg, S.D., Salles, J.F., 2015. Functional redundancy and ecosystem function - the soil 605 microbiota as a case study. In: Biodiversity in Ecosystems - Linking Structure and 606 Function (Eds. Blanco, J.., Lo, Y.H., Roy, S.), IntechOpen Ltd., London, UK,

607 Lauber, C.L., Hamady, M., Knight, R., Fierer, N., 2009. Pyrosequencing-based assessment of 608 soil $\mathrm{pH}$ as a predictor of soil bacterial community structure at the continental Scale. 609

Lin, C.Y., Viant, M.R., Tjeerdema, R.S., 2006. Metabolomics: Methodologies and applications in the environmental sciences. Journal of Pesticide Science 31, 245-251

Link, H., Fuhrer, T., Gerosa, L., Zamboni, N., Sauer, U., 2015. Real-time metabolome profiling of the metabolic switch between starvation and growth. Nature Methods 12, 1091-1097.

Mahieu, N.G., Patti, G.J., 2017. Systems-level annotation of a metabolomics data set reduces 25000 features to fewer than 1000 unique metabolites. Analytical Chemistry 89, 1039710406.

Min, K., Showman, L., Perera, A., Arora, R., 2018. Salicylic acid-induced freezing tolerance in spinach (Spinacia oleracea L.) leaves explored through metabolite profiling. Environmental and Experimental Botany 156, 214-227.

620

Miranda, K.M., Espey, M.G., Wink, D.A., 2001. A rapid, simple spectrophotometric method for simultaneous detection of nitrate and nitrite. Nitric Oxide 5, 62-71.

Mulvaney, R.L., 1996. Nitrogen - inorganic forms. In: Methods of Soil Analysis, Part 3, (Ed. Sparks, D.L.). Soil Science Society of America, American Society of Agronomy,

Murphy, J., Riley, J.P., 1962. A modified single solution method for determination of 626 phosphate in natural waters. Analytica Chimica Acta 27, 31-36.

627

Osborne, J.W., Costello, A.B., 2004. Sample size and subject to item ratio in principal components analysis. Practical Assessment, Research and Evaluation 9, 8. 
629 Pan, Z., Raftery, D., 2007. Comparing and combining NMR spectroscopy and mass 630 spectrometry in metabolomics. Analytical and Bioanalytical Chemistry 387, 525-527.

631 Patti, G.J., Yanes, O., Siuzdak, G., 2012. Metabolomics: the apogee of the omics trilogy. 632 Nature Reviews Molecular Cell Biology 13, 263-269.

633 Pershina, E. V., Ivanova, E.A., Korvigo, I.O., Chirak, E.L., Sergaliev, N.H., Abakumov, E. V., 634 Provorov, N.A., Andronov, E.E., 2018. Investigation of the core microbiome in main soil 635 types from the East European plain. Science of the Total Environment 631-632, 1421636 1430.

Preston, M.D., Basiliko, N., 2016. Carbon mineralization in peatlands: Does the soil microbial community composition matter? Geomicrobiology Journal 33, 151-162.

639 Psychogios, N., Hau, D.D., Peng, J., Guo, A.C., Mandal, R., Bouatra, S., Sinelnikov, I., 640 Krishnamurthy, R., Eisner, R., Gautam, B., Young, N., Xia, J., Knox, C., Dong, E., Huang, 641 P., Hollander, Z., Pedersen, T.L., Smith, S.R., Bamforth, F., Greiner, R., McManus, B., Newman, J.W., Goodfriend, T., Wishart, D.S., 2011. The human serum metabolome.

Schloter, M., Nannipieri, P., Sørensen, S.J., van Elsas, J.D., 2018. Microbial indicators for soil 645 quality. Biology and Fertility of Soils 54, 1-10.

646

Seaton, F.M., Barrett G., Burden, A., Creer, S., Dos Santos Pereira, G., Fitos, E., Garbutt, A., 647 Griffiths, R.I., Henrys, P., Jones, D.L., Keith, A., Lebron, I., Maskell, L., Reinsch, S., metabolite profiling of two genotypes of barley (Hordeum vulgare L.) reveals differences in response to short-term salt stress. Journal of Experimental Botany 67, 3731-3745. 
Simfukwe, P., Hill, P.W., Emmett, B.A., Jones, D.L., 2011. Soil classification provides a poor indicator of carbon turnover rates in soil. Soil Biology \& Biochemistry 43, 1688-1696.

Sumner, L.W., Lei, Z., Nikolau, B.J., Saito, K., 2015. Modern plant metabolomics: advanced natural product gene discoveries, improved technologies, and future prospects. Natural Products Reports 32, 212-219.

Swenson, T.L., Jenkins, S., Bowen, B.P., Northen, T.R., 2015. Untargeted soil metabolomics methods for analysis of extractable organic matter. Soil Biology \& Biochemistry 80, 189198.

Tang, J., 2011. Microbial metabolomics. Current Genomics 12, 391-403.

Trauger, S.A., Kalisak, E., Kalisiak, J., Morita, H., Weinberg, M. V., Menon, A.L., Poole II, F.L., Adams, M.W.W., Siuzdak, G., 2008. Correlating the transcriptome, proteome, and metabolome in the environmental adaptation of a hyperthermophile. Journal of Proteome Research 7, 1027-1035.

Vinayavekhin, N., Saghatelian, A., 2010. Untargeted metabolomics. Current Protocols in Molecular Biology 90, 30.1.1-30.1.24.

Wang, X., Yang, F., Zhang, Y., Xu, G., Liu, Y., Tian, J., Gao, P., 2015. Evaluation and optimization of sample preparation methods for metabolic profiling analysis of Escherichia coli. Electrophoresis 36, 2140-2147.

Warren, C.R., 2014. Response of osmolytes in soil to drying and rewetting. Soil Biology \& Biochemistry 70, 22-32.

Wellerdiek, M., Winterhoff, D., Reule, W., Brandner, J., Oldiges, M., 2009. Metabolic quenching of Corynebacterium glutamicum: efficiency of methods and impact of cold shock. Bioprocess and Biosystems Engineering 32, 581-592.

Wilson, I.D., Plumb, R., Granger, J., Major, H., Williams, R., Lenz, E.M., 2005. HPLC-MSbased methods for the study of metabolomics. Journal of Chromatography B 817, 67-76. 
679 Wishart, D.S., 2019. Metabolomics for investigating physiological and pathophysiological $680 \quad$ processes. Physiological Reviews 99, 1819-1875.

681 Zhao, L.J., Zhang, H.L., White, J.C., Chen, X.Q., Li, H.B., Qu, X.L., Ji, R., 2019. 682 Metabolomics reveals that engineered nanomaterial exposure in soil alters both soil 683 rhizosphere metabolite profiles and maize metabolic pathways. Environmental Science $684 \quad$ Nano 6, 1716-1727.

685 Žifčáková, L., Větrovský, T., Howe, A., Baldrian, P., 2016. Microbial activity in forest soil 686 reflects the changes in ecosystem properties between summer and winter. Environmental 687 Microbiology 18, 288-301. 